Board of Governors of the Federal Reserve System

International Finance Discussion Papers

Number 1006

September 2010

Has International Financial Co-Movement Changed? Emerging Markets in the 2007-2009 Financial Crisis

\author{
John Ammer, Fang Cai, and Chiara Scotti
}

NOTE: International Finance Discussion Papers are preliminary materials circulated to stimulate discussion and critical comment. References to International Finance Discussion Papers (other than an acknowledgment that the writer has had access to unpublished material) should be cleared with the author or authors. Recent IFDPs are available on the Web at www.federalreserve.gov/pubs/ifdp/. This paper can be downloaded without charge from the Social Science Research Network electronic library at www.ssrn.com. 


\title{
Has International Financial Co-Movement Changed? Emerging Markets in the 2007-2009 Financial Crisis
}

\author{
John Ammer, Fang Cai, and Chiara Scotti*
}

\begin{abstract}
Emerging market (EM) assets have historically been regarded as inherently risky and particularly vulnerable to international shocks that result in a general increase in investor risk perceptions. In this paper, we assess the ongoing relevance of this view by examining the linkages between EM and non-EM stock and bond markets in the past two decades, with a focus on how these relationships played out during the global financial crisis of 2007-2009. We evaluate how these linkages have evolved over the period 1992-2009, through statistical tests of whether the volatility of EM financial markets changed - either in their response to international shocks originating in advanced economy markets or in their independent fluctuations. We find that over the longer period EM bond and stock prices have on average moved in the same direction as the prices of non-EM risky assets, and this co-movement has persisted. However, these relationships have evolved somewhat over time. Both EM sensitivity to international shocks and EM-specific volatility in EM sovereign bond spreads appear to have decreased over time, consistent with the greater fundamental stability of EM economies and perhaps a reduced inclination by investors to sell off EM assets in response to a rise in risk perceptions. Somewhat in contrast, while an upward trend in co-variation between EM and non-EM stock prices suggests an increasing degree of global market integration, idiosyncratic volatility has declined, consistent with a diminished level of locally-driven risk in these markets. In addition, the response of EM asset prices to the latest financial crisis appears to be moderate in comparison to historical experience. This evidence may reflect reduced EM vulnerability to external shocks in general, which is consistent with some encouraging improvements in the underlying fundamentals of EM economies over the decade preceding the onset of the crisis.
\end{abstract}

Keywords: contagion, yield spreads

JEL classifications: G01, F36, G15, G12

* The authors are staff economists in the Division of International Finance, Board of Governors of the Federal Reserve System, Washington, D.C. 20551 U.S.A. The views in this paper are solely the responsibility of the authors and should not be interpreted as reflecting the views of the Board of Governors of the Federal Reserve System or of any other person associated with the Federal Reserve System. The authors wish to thank Jane Haltmaier and Nick Klagge for their contributions to an earlier project that this work extends, Daniel Beltran and Steve Kamin for helpful comments, and Michael Gulick for excellent research assistance. 


\section{A Brief Review of the Events}

As shown in Figure 1, emerging-market (EM) stock price indexes followed a relatively volatile path over 1992-2009, and they also have exhibited substantial co-movement with advanced-economy stock markets, as has been documented in a number of prior studies. Similarly, EM sovereign bond spreads also have fluctuated sharply over time and tended to move quite closely with U.S. high-yield corporate spreads. Against this historical context, the onset of the financial crisis that originated in the United States in the summer of 2007 reverberated promptly in EM financial markets. EM stock prices and bond yields started to deteriorate in July 2007 along with non-EM market prices in response to growing concern about sub-prime mortgage loans. EM financial indicators worsened after a number of adverse news events that followed, such as the August 2007 announcement by French bank BNP Paribas of a suspension of withdrawals from some of its managed funds, citing exposure to illiquid sub-prime assets that had become difficult to mark to market value.

Increasing concerns over the strength of the U.S. economy contributed to another downturn in these indicators at the end of October 2007, but in the early stages of the crisis, EM financial markets seemed atypically buoyant, with international spill-over to this point relatively muted in magnitude, in comparison to the historical experience, in which EM markets had tended to crash the hardest. It was not until the second half of 2008 and the first quarter of 2009 that EM financial indicators worsened significantly, relative to pre-crisis levels. At this point, stock prices plummeted and bond prices skyrocketed in advanced and EM economies alike, as credit markets froze following Lehman's bankruptcy and amid mounting concerns about the solvency of financial institutions and the global economic outlook. However, EM financial prices generally fared no worse in the darkest days of the crisis than markets elsewhere, and EM markets subsequently rebounded more rapidly and robustly in the last ten months of 2009 than their advanced-economy counterparts.

The overall picture of EM financial markets through the 2007-2009 financial crisis appears to meaningfully reflect a reduced sensitivity of EM economies to external shocks going into the crisis, in comparison to past dynamics. Accordingly, our analysis is motivated by the question of what has changed over the years for the EM economies and whether their new-found resilience is likely to endure. 


\section{Improvements in Underlying Fundamentals}

One point that seems indisputable is that many EM economies appear to have, with help from improved policy choices, become more stable and structurally resilient over the decade preceding the onset of the financial crisis. As documented in the first row of Table 1 , the average EM inflation rate dropped from 18.7 percent in 1996 to 5.2 percent in 2006, reflecting an increased policy focus on controlling inflation, in many cases through explicit inflation-targeting regimes. Progress in reducing inflation rates has been particularly dramatic in a number of eastern European and Latin American economies. Fiscal balances have also improved, and were at manageable levels by 2006 in most of the important EM economies. Furthermore, current account surpluses had become the norm across much of emerging Asia and Latin America, and many countries have stockpiled large amounts of foreign exchange reserves. With less need for international financing, the ratio of external debt to GDP generally declined in emerging Asia and Latin America. In addition, against a background of increasing institutional and macroeconomic stability, domestic sources of credit have tended to expand more rapidly than GDP, further reducing the dependence of EM economies on external capital flows. ${ }^{1}$

It is also worth noting that the crisis in 2007-2009 departed somewhat from past experience in terms of relatively muted EM exchange rate volatility. Most major EM countries now have flexible exchange rate regimes (at least in the downward direction), which means fewer currencies have overvalued and thus been vulnerable to a sharp depreciation. In contrast, some of the EM economies that had seen the largest declines in currency values during past turmoil periods were countries that were financing sizable current account deficits to a large extent through short-term capital inflows.

Given all this, it is not surprising that EM economies would be less vulnerable to abrupt shifts in global risk perceptions than in the past. Probably at least in part as a result of efforts by institutions such as the International Monetary Fund (IMF) and the Bank for International

\footnotetext{
${ }^{1}$ However, credit growth, when rapid and undisciplined often had been associated with increased risk in earlier crises. Furthermore, in the crisis of 2007-2009, some of the smaller EM economies, notably the Baltic States, experienced heightened turmoil after the collapse of credit booms that had been financed from abroad. In addition, much-wealthier Iceland was rocked by the fallout from a reckless expansion of international intermediation on the part of its banks.
} 
Settlements (BIS) to promote improvements in the quality and consistency of data, transparency also appears to have improved for EM economies. In particular, there is some evidence that investors increasingly have been able to distinguish among different countries on the basis of fundamental factors, with countries that are perceived as more vulnerable (for example, Greece in 2009-2010) seeing more adverse changes in asset prices during an episode of financial turbulence. Overall, the evidence suggests that investors consider most EM economies to be fairly sound. This theme of increasing stability is apparent in the longer-term perspective on EM asset prices that we offer in the next section.

\section{Emerging Market Asset Price Dynamics}

Emerging market assets have historically been regarded as inherently risky, with their prices tending to react along with those of other risky assets, such as U.S. high-yield corporate bonds, particularly when international shocks result in a general increase in investor risk perceptions. However, there is some evidence that this relationship has changed. Figure 2 shows yield spreads for Merrill Lynch indexes of dollar-denominated EM sovereign bonds and U.S. (high-yield) corporate bonds since early 1992. Although EM sovereign spreads were high and quite volatile at times in the 1990s and early 2000s, the exhibit shows a distinct downward trend in both their level and volatility in the past few years, while the corresponding overall trends for U.S. corporate spreads are much less clear. Furthermore, the EM sovereign spreads in the exhibit understate the improvement in credit quality because of compositional changes in the series -- several countries (including China, Korea, and Chile) have been dropped from Merrill Lynch's EM sovereign indexes because credit rating upgrades made them ineligible for the inclusion criteria, while some riskier countries have been added to the indexes following their maiden international bond issues. These facts suggest that investor perceptions of EM credit risk have moderated over the past decade along with the improvement in EM fundamentals documented in the previous section.

The statistical analysis presented below is related to a substantial literature on spillovers and contagion in international capital markets. Many studies, for example, Cheung and Mak (1992), Liu and Pan (1997), Wu and Su (1998), and Cha and Oh (2000), report that the U.S. market is a global factor and the single most influential market in the world, affecting both 
developed and emerging markets. The identification of channels of shock transmission across countries is, for instance, discussed in Dungey, Fry, Gonzalez-Hermosillo and Martin (2005), Dornbusch, Park and Claessens (2000) and Pericoli and Sbracia (2003). Dungey, Fry, GonzalezHermosillo and Martin (2005, 2006) and Kaminsky and Reinhart (2003), Beirne, Caporale, Schulze-Ghattas and Spagnolo (2008) examine volatility spillovers from mature to EM countries and test for their changes during crisis periods. In this context, a large body of literature investigates conditional correlations during crisis periods in order to examine any possible breaks in the underlying data. Examples include Forbes and Rigobon (2002), King and Wadhwani (1990), King, Sentana, and Wadhwani (1994), Bekaert, Harvey, and Ng (2005), Caporale, Cippollini, and Spagnolo (2005). Coudert and Gex (2007) conclude that investors' risk appetite can rapidly change during financial crises when seemingly unrelated asset markets feel the impact by seemingly unrelated financial shocks. A closely related study by Frank and Hesse (2009) analyzes potential financial linkages between liquidity and bank solvency measures in advanced economies, such as stress in the inter-bank market, market volatility and solvency concerns of large financial institutions with emerging market stock indices, bond spreads and CDS measures. Carey et al. (2010) focuses on the crisis of 2007-2009, with an empirical investigation of the macroeconomic determinants of the impact on credit default swap premiums and stock prices, across both EM and non-EM economies, distinguishing between indexes of financial and non-financial firms.

\section{Linkages between EM and advanced economy stock and bond markets}

We begin with the relationship between EM sovereign spreads and U.S. high-yield corporate bond spreads, as indicated by the following equation:

$$
\left(\Delta p_{t}^{\text {EM.Sovereign }}-\Delta p_{t}^{\text {Treasury }}\right)=\alpha+\beta_{0} \cdot\left(\Delta p_{t}^{\text {U.S.Corporate }}-\Delta p_{t}^{\text {Treasury }}\right)+\varepsilon_{t}
$$

The parenthetical expressions represent the difference between the change in the log price index for a category of risky bonds (EM sovereign or U.S. corporate) and the change in the log price of a U.S. Treasury bond of similar maturity. These relative price change measures essentially capture changes in the yield spread. For the U.S. high-yield corporate bond index, which has an 
effective duration of about 5 years, a percentage point increase in the relative price change corresponds to a decline in the spread of about 20 basis points. ${ }^{2}$ We first examine this relationship over the whole 18-year period (1992-2009); later we will turn to the question of whether it has changed in recent years. It should be noted that this expression represents correlation, but not necessarily causation. Both spreads might react to common shocks, or U.S. spreads might be impacted by events originating in emerging markets. As shown in Table 2, all of the slope coefficients for 1992-2009 are positive and statistically significant. EM sovereign bond prices moved less than one-for-one with U.S. high-yield corporate bonds over this period.

Next we look at the relationship between EM stock prices and financial markets in advanced countries, which can offer a more direct window into the impact of external shocks on the private sector in these countries than does the relationship between bond yields examined above. The standard approach is to assess the linkage between EM and non-EM stock price indexes, which we do below. However, given that the financial turmoil had its seeds in U.S. debt markets, it is also useful to consider the relationship between EM stock prices and U.S. credit markets. In particular, we use the following regression specification to assess the extent to which EM stock price indexes have co-moved with U.S. high-yield corporate bonds:

$$
\Delta p_{t}^{\text {EM.Stock }}=\alpha+\beta_{0} \cdot\left(\Delta p_{t}^{\text {U.S.Corporate }}-\Delta p_{t}^{\text {Treasury }}\right)+\varepsilon_{t}
$$

Table 3 shows estimates of (2) for four EM stock price indexes. For every region EM stock prices move more than one-for-one with U.S. corporate bond prices, and the results are statistically significant. Accordingly, we should expect spillovers between these markets to be the rule, rather than the exception.

Returning to the relationship between EM and non-EM equity prices, we estimate the following specification:

$$
\Delta p_{t}^{E M \cdot \text { Stock }}=\alpha+\beta_{0} \cdot \Delta p_{t}^{\text {non-EM.Stock }}+\varepsilon_{t}
$$

\footnotetext{
${ }^{2}$ The practical advantage of using log changes in bond price indexes as a proxy for changes in spreads -- rather than working directly with the yield spread series -- is that, unlike the spread, the price index is constructed so that it does not have a jump whenever there is a structural break as a result of a new bond being added to the index. We do not have enough information about the U.S. corporate index to correct for these structural breaks before 1997.
} 
Table 4 shows estimates of (3) for a broad EM stock index and three regional sub-indices. All four move more than one-for-one with the log change in the MSCI (non-EM) World stock price index. In sum, the estimates reported in Tables 1, 2, and 3 confirm the notion that, over the past 18 years, EM asset prices have on average moved in the same direction as other risky asset prices and EM stock prices are more volatile than safer assets such as advanced economy stocks.

\section{Have these linkages changed over time?}

Next we turn to the question of whether these relationships have changed over time, with EM asset returns becoming either less sensitive to external shocks, less prone to locally-driven volatility, or perhaps both. We begin with sovereign bond prices. The upper panel of Figure 3 shows estimates of the slope coefficient $\left(\beta_{0}\right)$ from equation (1) (EM sovereign bond price changes on U.S. corporate bond price changes) from 25-month rolling regressions. The slope coefficients for the various EM regions vary substantially over time but move closely together. In particular, EM sovereign bonds appeared to be most highly correlated with U.S. high yield bonds during the 1997 Asian Crisis and 1998 Russian and LTCM Crises. It is difficult to discern any longer term trend in the response of EM spreads to U.S. corporate spreads, although some downward movement may be evident.

The lower panel of Figure 3 shows the standard errors of the residuals from these regressions. These standard errors may be interpreted as the volatility of EM bond spreads that is not explained by movements in U.S. corporate spreads. Elevated levels around the 1994-1995 Tequila, 1997 Asian, 1998 Russian and LTCM, 2001 Argentina, and 2002 Brazil crises are consistent with the EM economies being at least partly the source of their own pain during these events.

There also appears to be a downward trend in idiosyncratic volatility in sovereign bond prices in all three regions. We assess this trend more formally by augmenting our regression specification (1) to allow both $\beta$ and the variance of the residual to trend over time.

$$
\left(\Delta p_{t}^{\text {EM.Sovereign }}-\Delta p_{t}^{\text {Treasury }}\right)=\alpha+\left(\beta_{0}+\beta_{t} \cdot t\right) \cdot\left(\Delta p_{t}^{\text {U.S.Corporate }}-\Delta p_{t}^{\text {Treasury }}\right)+\varepsilon_{t}
$$

and 


$$
E\left(\varepsilon_{t}^{2}\right)=V_{0}+V_{t} \cdot t
$$

An advantage of this framework is that it allows us to decompose a decrease in overall price volatility into reduced sensitivity to global shocks and lower EM-specific volatility. Table 5 reports estimates of the system (4) and (5). For all four sovereign bond indices, our negative point estimates of $\beta_{t}$ and $V_{t}$ suggest both reduced sensitivity to international shocks and a reduction in EM-specific risk. Most of the coefficients are significant at the 5 percent level. These results are consistent with the greater fundamental stability of EM economies and reduced inclination by investors to sell off EM assets in response to a rise in risk perceptions.

A natural question is whether the trends observed in EM bond prices are also evident in EM stock prices. Figure 4 shows slope coefficients and residual standard errors for rolling regressions of EM stock prices on U.S. corporate bond price changes (equation 2). Both the slope coefficients and residual volatility have trended down from peaks reached during the bout of EM financial crises in the latter half of the 1990s, although the slope estimates turned upward in 2005-2006. We also assess the direction in covariance and residual risk more systematically by augmenting equation (2) to allow trends in the slope coefficient and residual volatility.

$$
\Delta p_{t}^{\text {EM.Stock }}=\alpha+\left(\beta_{0}+\beta_{t} \cdot t\right) \cdot\left(\Delta p_{t}^{\text {U.S.Corporate }}-\Delta p_{t}^{\text {Treasury }}\right)+\varepsilon_{t}
$$

and

$$
E\left(\varepsilon_{t}^{2}\right)=V_{0}+V_{t} \cdot t
$$

Table 6 reports estimates of the system (6) and (7). Although most of the trend coefficients $\left(\beta_{t}\right.$ and $V_{t}$ ) are not statistically significant, they are generally negative in sign, which we take to be further evidence of downward trends in EM vulnerability to external credit market shocks and in EM-specific risk.

Figure 5 addresses trends in international stock market co-movement (equation 3), showing slope coefficients and residual standard errors for rolling regressions of EM stock prices on the World stock index. Interestingly, they go in opposite directions, with EM stock prices showing increasing integration with the rest of the world, but attenuated idiosyncratic volatility. We obtain similar results from the estimation of a system with trends for the full period, i.e.:

$$
\Delta p_{t}^{\text {EM. Stock }}=\alpha+\left(\beta_{0}+\beta_{t} \cdot t\right) \cdot \Delta p_{t}^{\text {non-EM-Stock }}+\varepsilon_{t}
$$


and

$$
E\left(\varepsilon_{t}^{2}\right)=V_{0}+V_{t} \cdot t
$$

As reported in Table 7, the estimated slope $\beta_{t}$ rises over time while the residual variance $V_{t}$ falls; these results are statistically significant at the 5 percent level in almost all cases.

The striking result that EM stock prices appear to be moving more closely with those of advanced countries while at the same time their volatility has declined is suggestive of an increasing level of maturity in these markets. In other words, EM stocks appear to be becoming more like those of advanced countries, moving in tandem in response to common shocks while at the same time exhibiting greater stability. These results are consistent with the others presented in this section, suggesting that at least on an everyday basis, the perceived riskiness of EM assets appears to be declining. However, the question still remains of what happens when markets are rattled by an unusually large shock, which is the subject of the next section.

\section{How do recent EM asset price dynamics compare to previous international shock episodes?}

In this section we compare changes in EM sovereign bond spreads and stock prices in the crisis of 2007-2009 to changes during previous periods when emerging markets suffered in the wake of significant international shocks. We define our comparison periods as those with large and abrupt drops in non-EM asset prices, identifying seven prior credit market episodes since 1992 when the U.S. high yield corporate bond price index dropped by at least 5 percentage points, net of the Treasury bond price index (see Appendix for more detail). The identified periods are listed in Table 8; the corresponding increases in U.S. corporate credit spreads (the first column) during these episodes range from 127 basis points to 441 basis points. The first episode encompasses the Russian and LTCM crises, but some of the others are more difficult to pin to discrete events. The largest single market movement in the table is for the mid-2002 event, which featured a surge in corporate defaults and bankruptcies, including WorldCom, and concerns about corporate governance and fraud that led to the passage of the Sarbanes-Oxley Act. The last episode, in the spring of 2005, was associated with concerns about the financial viability of two of the world's largest corporate borrowers, Ford and GM. 
The crisis of 2007-2009 is identified by our methodology as five distinct events in U.S. credit markets, separated by intervening pauses with partial, but then aborted, recoveries in U.S. credit spreads. The first of these abatements ran from the Federal Reserve's reduction in the discount rate in mid-August, 2007 to mid-October, 2007 and the second occurred between late November and late December of 2007. We also show price statistics for a period (June 5, 2007 to March 9, 2009) that encompasses all of these sub-periods -- this composite period marks the largest increase in U.S. high-yield bond spreads of the past 16 years -- 1456 basis points. They rose nearly as much in the fourth of the five sub-periods and the longest in duration (June 13, 2008 to December 16, 2008), reaching an all-time high at the end of this interval.

The remaining columns of Table 8 show changes in yield spreads for EM sovereign bond indexes for each period of interest. Interpretation of these figures is sometimes complicated by significant EM-specific developments also occurring during these periods. Nevertheless, only for the 1998 event did our broadest index of EM yield spreads rise more than U.S. corporate spreads. The spread for the broad EM index also increased sharply (more than 300 basis points) during the mid-2002 event. However, a substantial portion of this increase is directly attributable to soaring spreads for Brazil (which has one of the largest country weights in the index), as Socialist candidate and President-to-be Lula began to lead in polls, which triggered concerns that Brazil might fail to honor its external debt if he were elected. More generally, reactions in EM yield spreads to U.S. credit markets during stress periods appear to have decreased over time, consistent with the trend estimates reported in Table 5, and they were relatively muted in the 2007-2009 event periods, with EM sovereign spreads in all regions generally rising by less than half of the increase in U.S. high-yield corporate spreads.

Table 9 reports the results of a similar exercise for percent changes in the EM stock price indexes. Strikingly, the broad EM index was down 15 to 20 percent in five of the six U.S. credit market events that occurred between 1998 and 2002, with all three of the regional sub-indexes tending to be significantly affected. On average over the 7 episodes that precede the crisis of 2007-2009, EM stock prices tended to move more than the broad (All Sectors) non-EM World Index, consistent with the slope estimates reported in Tables 4 and 7. However, EM stock price losses were roughly similar to those in other markets during the 2007-2009 price declines, and with the help of a 35 percent rebound between mid-August and mid-October of 2007, the broad EM index declined slightly less than the non-EM World Index over the full June 2007 to March 
2009 period, as reported in the table. Given the increasing trend in the co-variation between EM and non-EM stock prices that was reported in Table 7, the relative resilience of EM equity markets is consistent with reduced EM vulnerability to external spillovers.

\section{Concluding Remarks}

The response of EM asset prices to the crisis of 2007-2009, which was centered on U.S. and European financial intermediaries, was fairly mild in comparison to historical experience. This outcome stands in striking contrast to past periods of financial turbulence, when capital flows typically turned sharply away from EM economies, often resulting in serious economic disruption. Furthermore, the muted response in EM financial markets seems particularly remarkable given that, prior to the onset of this year's turmoil, many EM asset prices had soared during 2002-2007 to unprecedented levels and thus seemed vulnerable to a downward correction.

Notwithstanding, our statistical analysis shows that in the crisis of 2007-2009, the declines in key EM asset values -- including sovereign bonds and stock market indexes -- were smaller than in episodes in the past, when investors retreating from risk seemed to sell off EM assets almost indiscriminately. This finding is consistent with econometric evidence that the responsiveness of EM asset prices to movements in U.S. high-yield corporate bond spreads has declined over the past decade. More generally, we are able to document a downward trend in EM asset price volatility -- particularly for sovereign bonds -- that appears to reflect an increasing resilience of EM economies to external shocks. Signs of increased stability are also apparent in conventional indicators of the vulnerability of EM economies; for example, debt ratios have declined and external balances had strengthened since the 1990s for most of these countries, and with monetary and fiscal policy generally on a steadier course, both inflation and fiscal balances moderated.

Thus, the recent resilience of emerging markets appears to reflect improvements in fundamentals rather than a decoupling from industrial-country markets. In fact, EM markets have become increasingly integrated with the rest of the world, a development that is reflected in stronger international stock price correlations. However, EM-specific stock market volatility has decreased since the 1990s. This apparent decline in risk may be related to one of the most important improvements in EM fundamentals -- a shift from fixed exchange rate regimes (once 
thought to provide an essential nominal anchor) to rates that are flexible at least in the downward direction (although many countries continue to resist appreciation). In the past, investors have often fled EM assets when a currency peg seemed vulnerable, fearing the consequences of a disorderly devaluation. In contrast, EM currency values were relatively resilient in the wake of the financial crisis of 2007-2009, and despite precipitous declines in export volumes in the second half of 2008, real activity in most EM economies recovered fairly quickly. This apparent pay-off from more prudent choices made by EM authorities since the 1990s should also bode well for future commitment to policies that promote stability. 


\section{References}

Beirne, J., G. M. Caporale, M. Schulze-Ghattas, and N. Spagnolo, 2008, “Volatility Spillovers and Contagion from Mature to Emerging Stock Markets,” IMF Working Paper 08/286 (Washington: International Monetary Fund).

Bekaert, G, C.R. Harvey, and A. Ng, 2005, “Market Integration and Contagion,” Journal of Business, Vol. 78, No. 1, pp. 39-9.

Caporale, G.M., N. Pittis, and N. Spagnolo, 2006, "Volatility Transmission and Financial Crises,” Journal of Economics and Finance, Vol. 30, No.3, pp.376-90.

Carey, M., L. Demarco, S. Kamin, U. Lel, and D. Silver, 2010, “Emerging Markets, Decoupling, and Financial Performance During the Crisis,” draft manuscript, Board of Governors of the Federal Reserve System (May 10).

Cha, B., and S. Oh, 2000, “The relationship between developed equity markets and the Pacific Basin’s emerging equity markets,” International Review of Economics and Finance, Vol. 9, pp. 299-322.

Cheung, Y. L., \&Mak, S. C., 1992, “The International Transmission of Stock Market Fluctuation between the Developed Markets and the Asian-Pacific Markets,” Applied Financial Economics, Vol. 2, 43-47.

Coudert, V., and M. Gex, 2007, “Does Risk Aversion Drive Financial Crises? Testing the Predictive Power of Empirical Indicators,” Centre d'Etudes Prospectives et d'Informations Internationales, Working Paper No. 2007-02.

Dornbusch, R., Y.C. Park, and S. Claessens, 2000, “Contagion: How it Spreads and How it can be Stopped,” World Bank Research Observer, Vol. 15, pp. 177-97. 
Dungey, M., R. Fry, B. González-Hermosillo, and V. Martin, 2005, “Empirical Modeling of Contagion: A Review of Methodologies,” Quantitative Finance, Vol. 5, pp. 9-24.

Dungey, M., R. Fry, B. González-Hermosillo, and V. Martin, 2006, “Contagion in International Bond Markets during the Russian and LTCM Crises,” Journal of Financial Stability, Vol. 2, pp. 1-27.

Forbes, K., and R. Rigobon, 2002, “No Contagion, Only Interdependence: Measuring Stock Market Co-movements,” Journal of Finance, Vol. 57, No. 5, pp. 2223-61.

Frank, N., and H. Hesse, 2009, "Financial Spillovers to Emerging Markets During the Global Financial Crisis”, IMF working paper WP/09/104.

Kaminsky, G.L., and C.M. Reinhart, 2003, “The Center and the Periphery: The Globalization of Financial Turmoil,” NBER Working Paper No. 9479 (Cambridge: National Bureau of Economic Research).

King, M., E. Sentana, and S. Wadhwani, 1994, "Volatility and Links between National Stock Markets,” Econometrica, Vol. 62, pp. 901-33.

King, M., and S. Wadhwani, 1990, “Transmission of Volatility between Stock Markets,” Review of Financial Studies, Vol. 3, No.1, pp. 5-33.

Liu, Y. A., and Pan, M., 1997, "Mean and Volatility Spillover Effects in the U.S. and PacificBasin Stock Markets,” Multinational Finance Journal, Vol. 1, 47-62.

Pericoli, M., and M. Sbracia, 2003, “A Primer on Financial Contagion,” Journal of Economic Surveys, Vol. 17, pp. 571-608.

Wu, C., \& Su, Y., 1998, “Dynamic Relations among International Stock Markets,” International Review of Economics and Finance, Vol. 7, pp. 63-84. 


\section{Appendix: Identifying and Defining Large Declines in U.S. Corporate Bond Markets}

- We begin with intervals of at least twenty days in which the ratio of the high yield bond price index to the 6-year Treasury bond price index declines by at least 5 percent.

- We eliminate most of the overlap in candidate periods by choosing only the ones that are "peak-to-trough”.

- We deem a period of decline to be completed after a "rebound" of 5 percent from the trough.

- We deem a period of decline to be completed after a "pause" of 20 or more trading days. A "pause" means that the ratio of the two indexes never fell below a (virtually flat) trendline that declines .025 percent per day since the proposed trough.

- We excise any interval at the beginning or end of a proposed period of decline for which the rate of decrease is less than .025 percent per day from the proposed peak.

- We merge any episodes that are less than 10 days apart. 
Figure 1

\section{Emerging Market Stock Prices}

Monthly

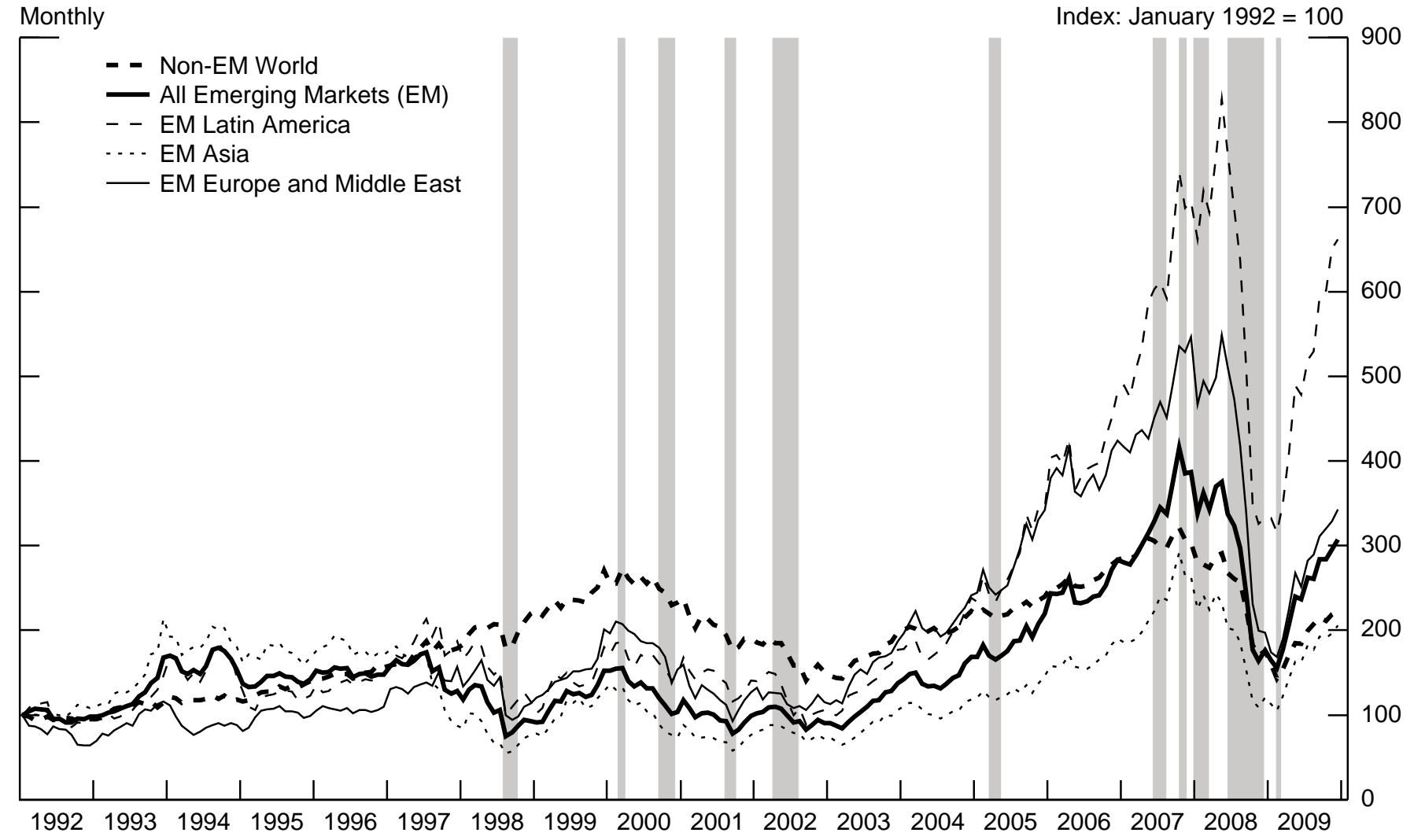

*Shaded areas correspond to episodes with large and abrupt drops in non-EM asset prices as identified in the Appendix. 
Figure 2

\section{Emerging Market Bond Yield Spreads}

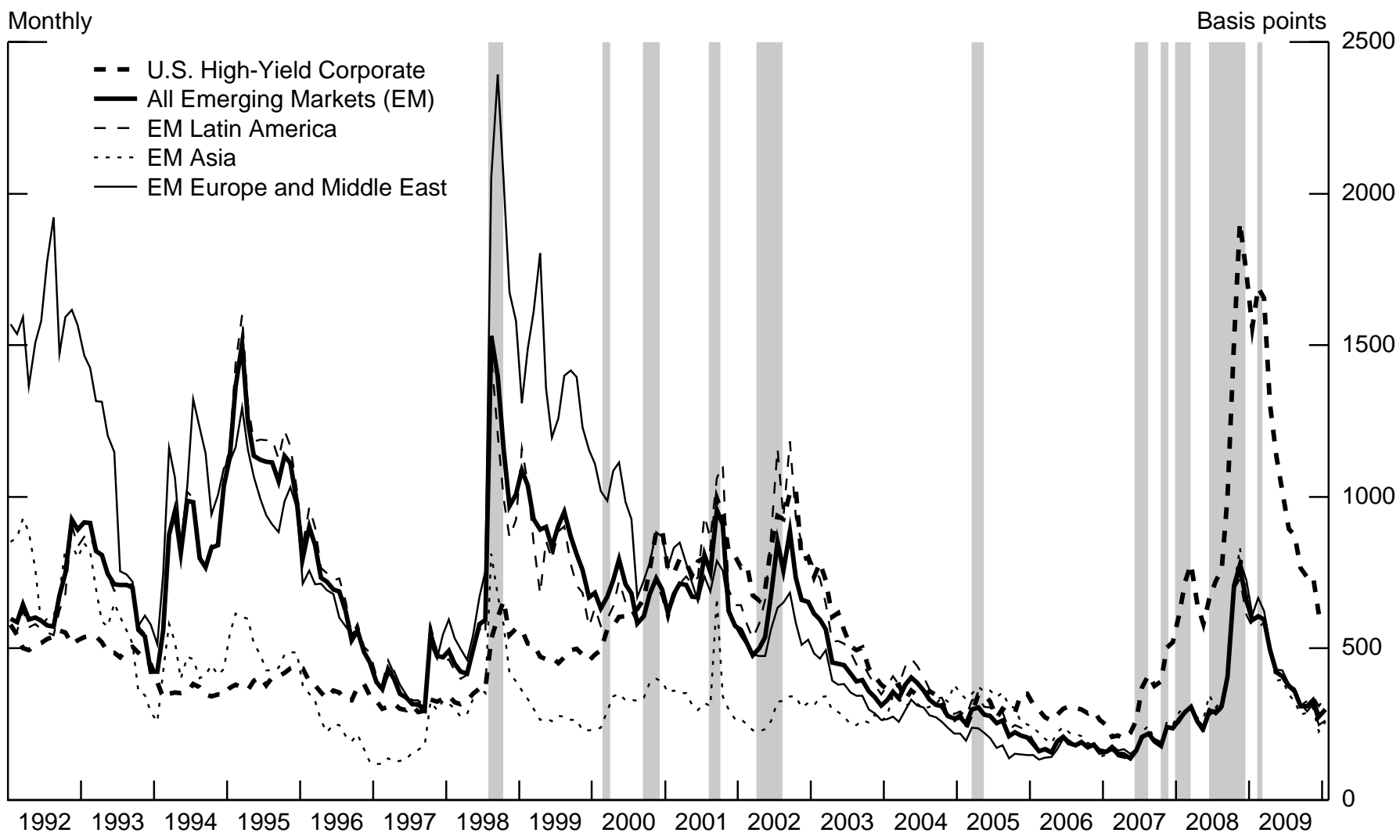

*Shaded areas correspond to episodes with large and abrupt drops in non-EM asset prices as identified in the Appendix. 


\section{Regressions of EM Sovereign Bond Price Changes on U.S. High-Yield Bond Price Changes}

Slope Coefficient Estimates

Monthly

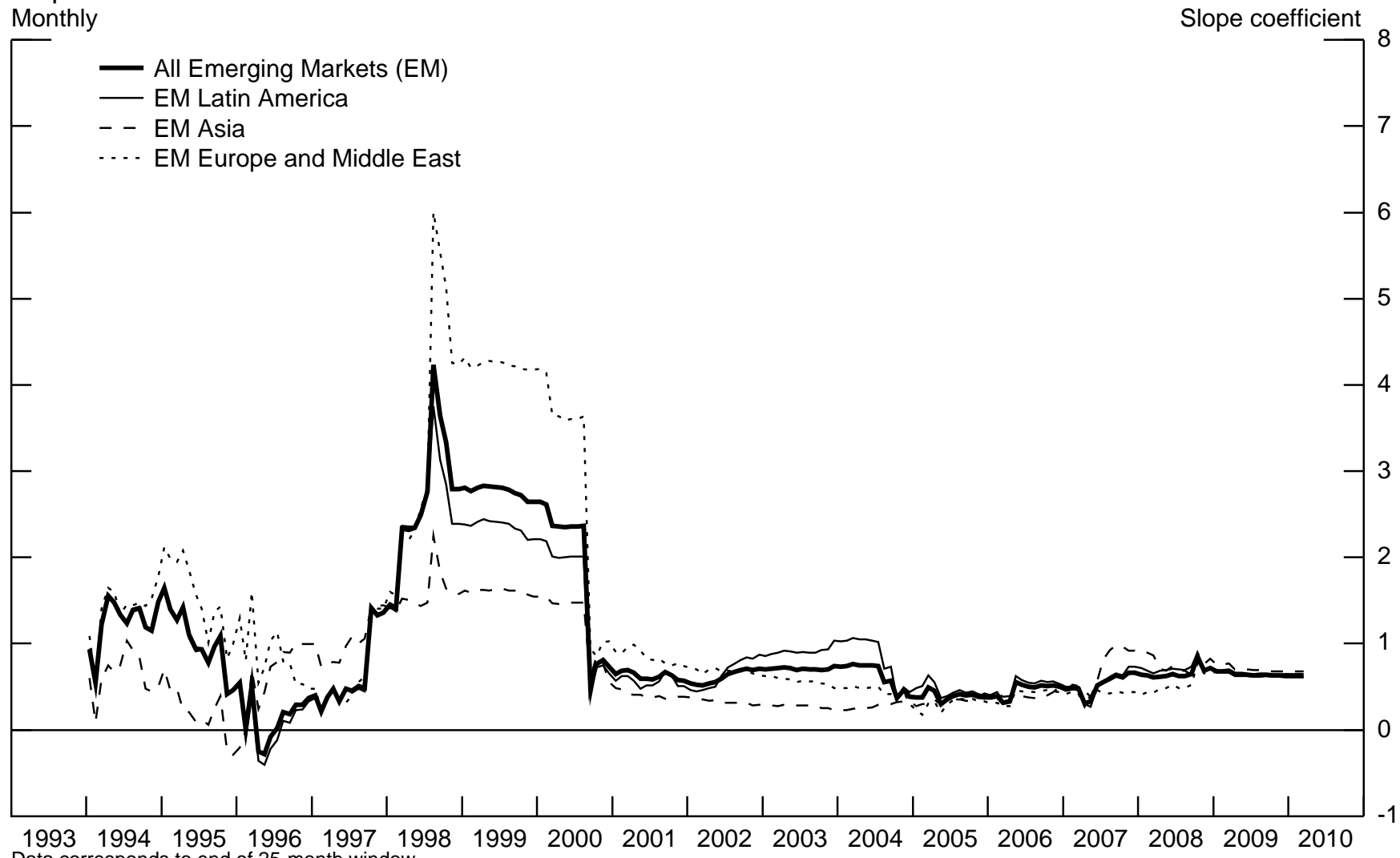
Data corresponds to end of 25-month window.

Residual Standard Errors

Monthly

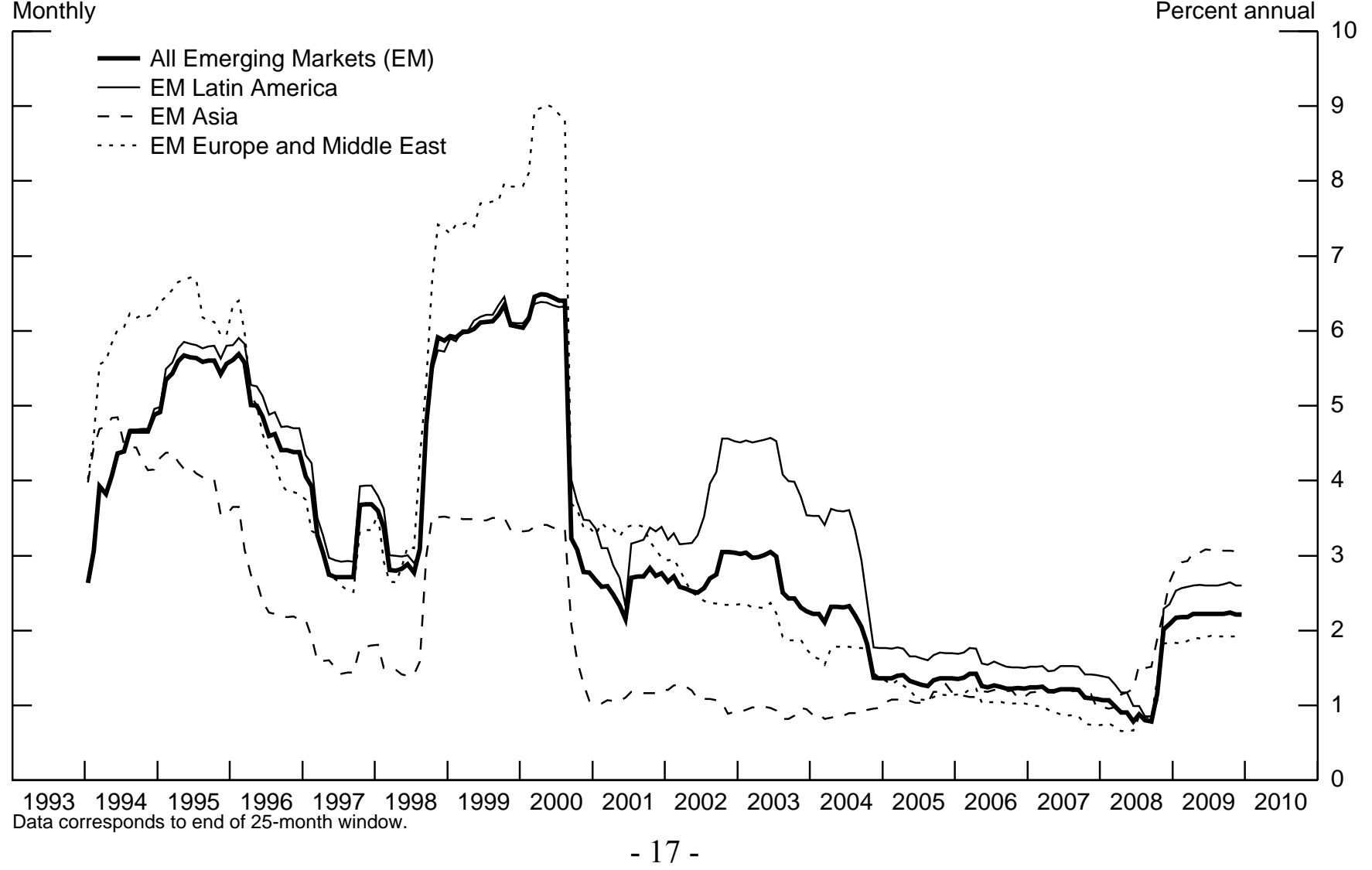


Figure 4

Regressions of EM Stock Price Changes on U.S. High-Yield Bond Price Changes

Slope Coefficient Estimates

Monthly

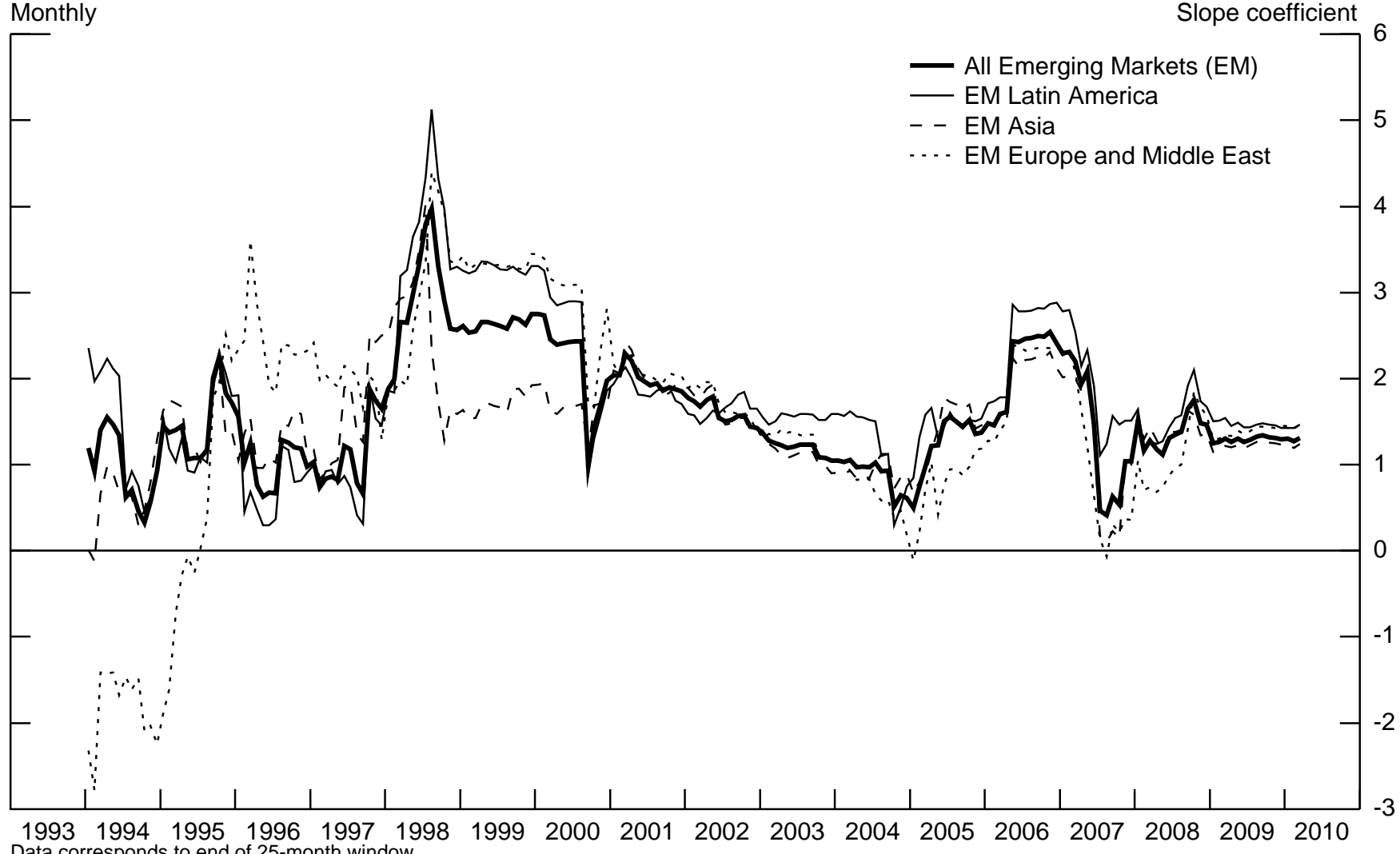
Data corresponds to end of 25-month window.

Residual Standard Errors

Monthly

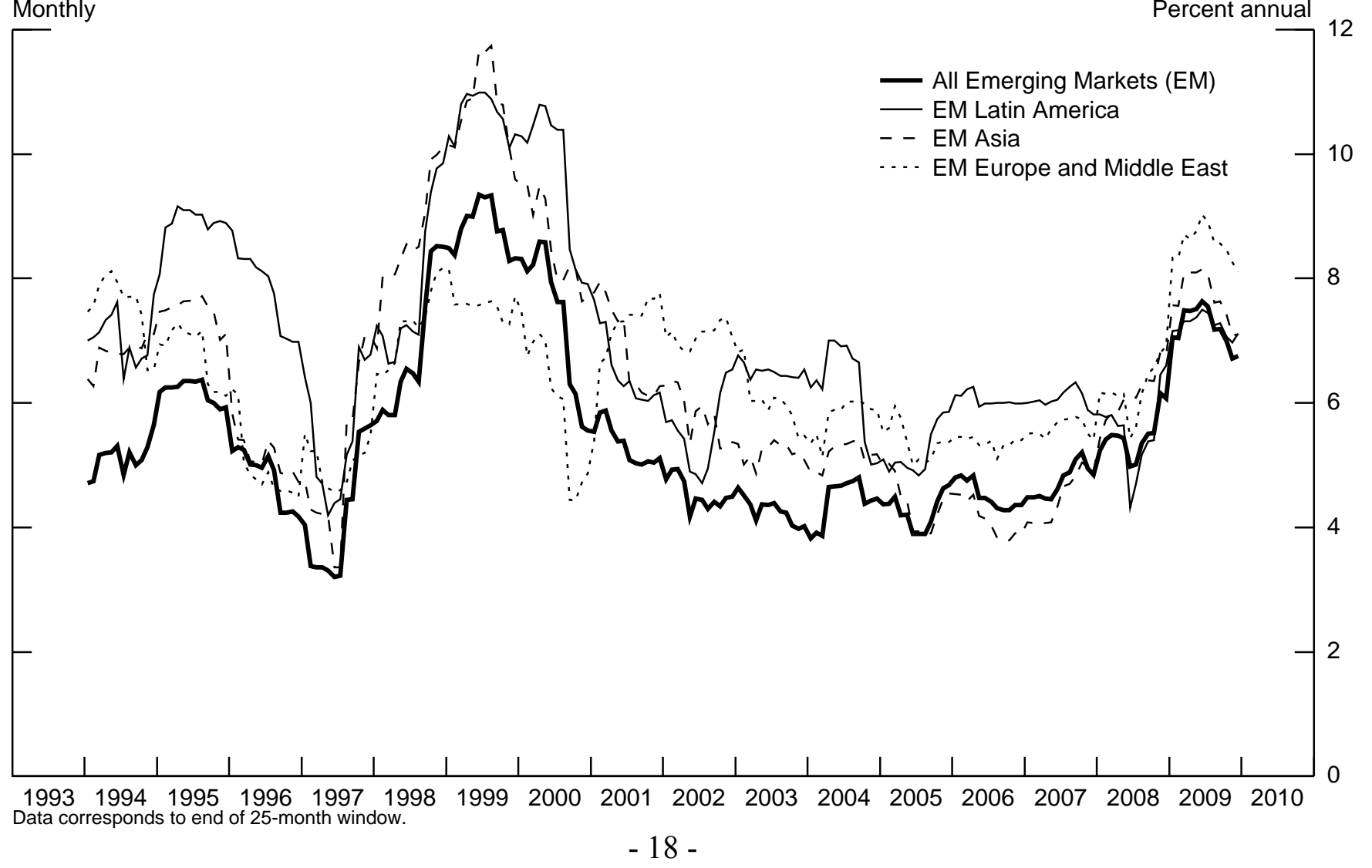


Figure 5

Regressions of EM Stock Price Changes on Non-EM World Stock Price Changes

Slope Coefficient Estimates

Monthly

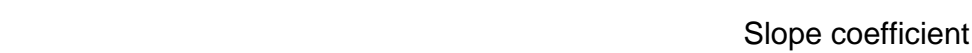

Slope coefficient

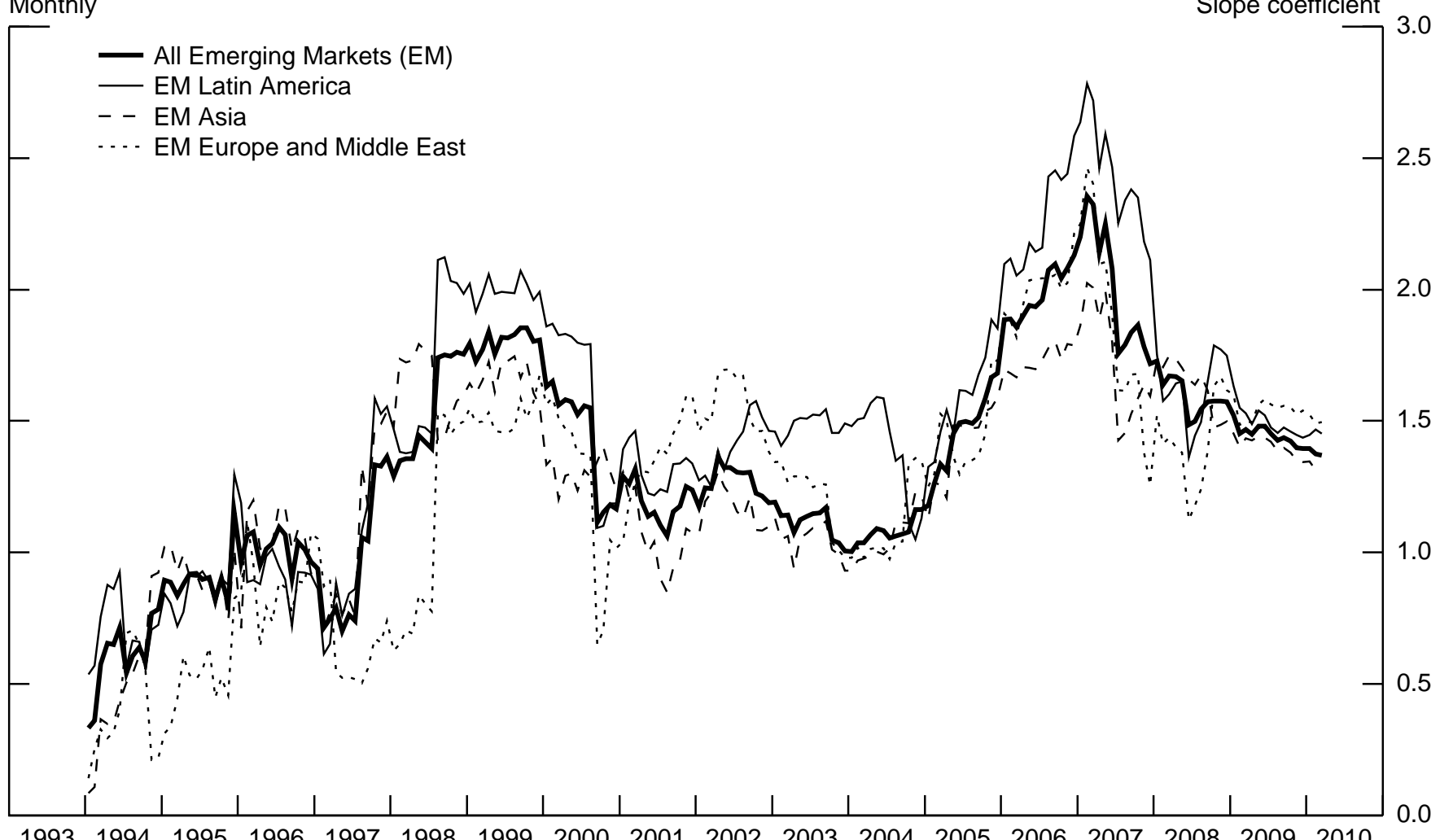

$\begin{array}{llllll}1993 & 1994 & 1995 & 1996 \quad 1997 \quad 1998\end{array}$

Residual Standard Errors

Monthly

Percent annual

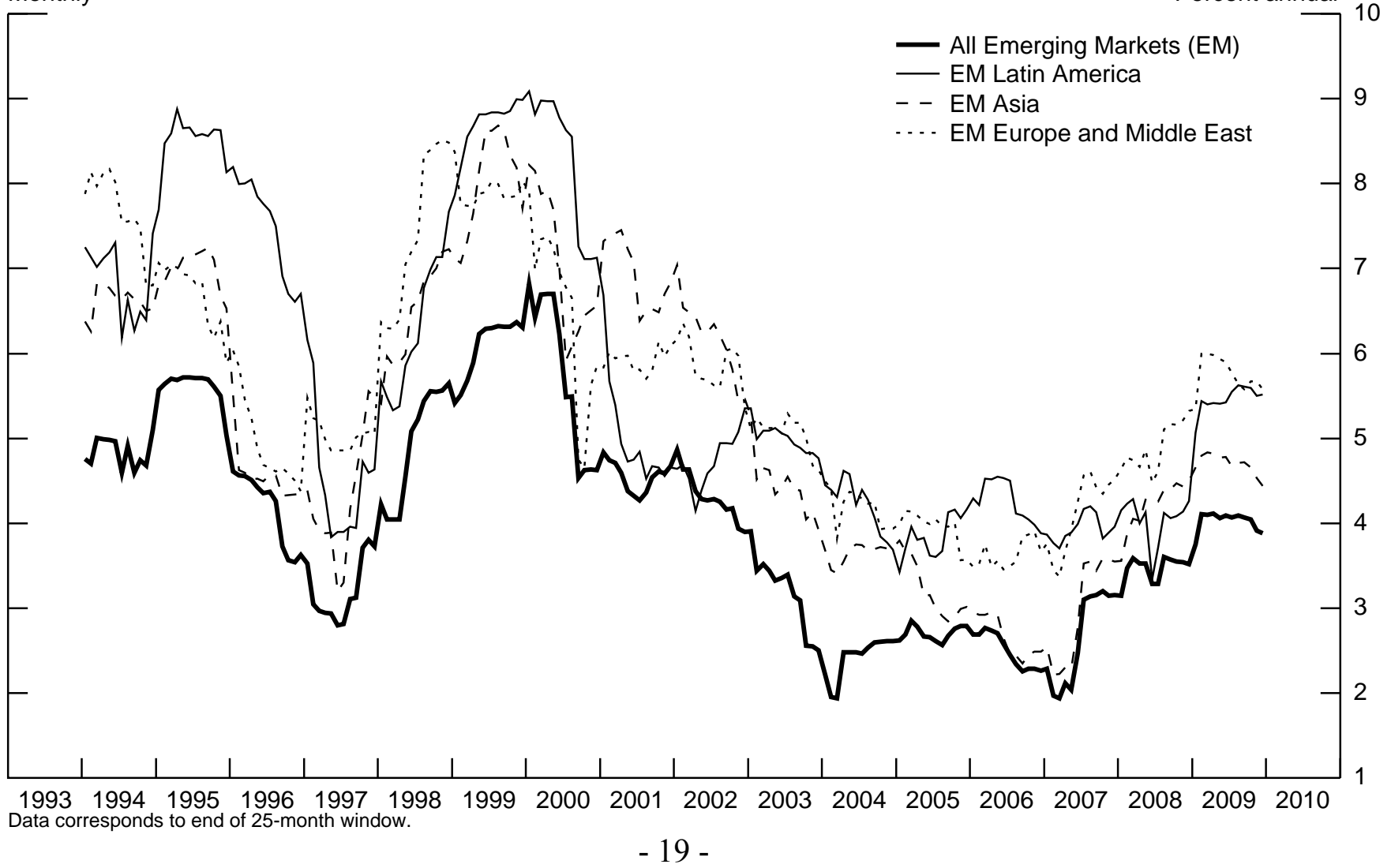


Table 1: Mean EM Fundamental Indicators*

\begin{tabular}{|c|c|c|c|c|c|c|c|c|}
\hline & & $\frac{\text { All }}{\text { rging }}$ & & I Asia & $\frac{\mathrm{EM}}{\underline{\mathrm{M}}}$ & $\frac{\text { Irope, }}{\text {-East, }}$ & & $\frac{\text { Latin }}{\text { erica }}$ \\
\hline & $\underline{1996}$ & $\underline{2006}$ & $\underline{1996}$ & $\underline{2006}$ & $\underline{1996}$ & $\underline{2006}$ & $\underline{1996}$ & $\underline{2006}$ \\
\hline Consumer Price Inflation (\%) & 18.7 & 5.2 & 6.7 & 4.0 & 23.9 & 5.9 & 25.6 & 5.7 \\
\hline Fiscal Balance / GDP (\%) & -2.5 & -1.2 & -1.5 & -1.6 & -4.5 & -2.3 & -1.6 & 0.2 \\
\hline Current Account / GDP (\%) & -2.4 & 1.8 & -3.8 & 4.1 & -2.3 & -1.4 & -1.2 & 2.8 \\
\hline Official Reserves / GDP (\%) & 12.2 & 21.1 & 13.9 & 32.3 & 11.9 & 18.8 & 10.9 & 12.1 \\
\hline External Debt / GDP (\%) & 40.2 & 36.7 & 37.2 & 29.0 & 38.6 & 47.7 & 44.8 & 33.5 \\
\hline Domestic Credit / GDP (\%) & 54.4 & 63.1 & 83.0 & 92.2 & 52.7 & 59.6 & 27.5 & 37.6 \\
\hline
\end{tabular}

* All Emerging Markets figures are means for 27 countries included in the MSCI all-EM stock index and/or the Merrill Lynch indexes of dollar-denominated EM sovereign bonds for which the relevant data were available. EM Asia includes China, India, Indonesia, Korea, Malaysia, Pakistan, Philippines, Taiwan, and Thailand. EM Europe Mid-East and Africa includes Czech Republic, Egypt, Hungary, Israel, Poland, Russia, South Africa, Turkey, and Ukraine. EM Latin America includes Argentina, Brazil, Chile, Colombia, Ecuador, Mexico, Peru, Uruguay, and Venezuela. 


\section{Table 2: Sensitivity of EM Sovereign Bond Prices to U.S. Corporate Bond Prices}

(January 1992 to December 2009)

$$
\left(\Delta p_{t}^{\text {EM.Sovereign }}-\Delta p_{t}^{\text {Treasury }}\right)=\alpha+\beta_{0} \cdot\left(\Delta p_{t}^{\text {U.S.Corporate }}-\Delta p_{t}^{\text {Treasury }}\right)+\varepsilon_{t}
$$

$\begin{array}{lcc}\underline{\text { EM Sovereign Bond Index }} & \underline{\beta_{0}} & \underline{\mathrm{R}^{2}} \\ \text { All Emerging Markets } & 0.772 & 0.294 \\ & (0.000) & \\ \text { Latin America } & 0.783 & 0.280 \\ & (0.000) & \\ \text { Asia } & 0.624 & 0.347 \\ & (0.000) & \\ \text { Europe, Mid-East, and Africa } & 0.842 & 0.227 \\ & (0.000) & \end{array}$

Notes: These regression estimates are based on month-end data on log changes in bond price indexes, less the log change in a price index for the 6-year U.S. Treasury bond. Bond indexes are from Merrill Lynch and measured in dollars. The figure in parentheses below each coefficient estimate is a P-value for a two-tailed test for a null hypothesis of a zero coefficient. 


\section{Table 3: Sensitivity of EM Stock Indexes to U.S. Corporate Bond Prices}

(January 1992 to December 2009)

$$
\Delta p_{t}^{E M \cdot S t o c k}=\alpha+\beta_{0} \cdot\left(\Delta p_{t}^{\text {U.S.Corporate }}-\Delta p_{t}^{\text {Treasury }}\right)+\varepsilon_{t}
$$

$\begin{array}{lcc}\text { EM Stock Price Index } & \underline{\beta_{0}} & \underline{\mathrm{R}^{2}} \\ \text { All Emerging Markets } & 1.400 & 0.368 \\ & (0.000) & \\ \text { Latin America } & 1.612 & 0.326 \\ & (0.000) & \\ \text { Asia } & 1.282 & 0.269 \\ & (0.000) & \\ \text { Europe, Mid-East, and Africa } & 1.481 & 0.311 \\ & (0.000) & \end{array}$

Notes: These regression estimates are based on month-end data on log changes in price indexes. The U.S. Treasury bond price index is for a 6-year maturity. Bond indexes are from Merrill Lynch and stock indexes are from MSCI, with both measured in dollars. The figure in parentheses below each coefficient estimate is a P-value for a two-tailed test for a null hypothesis of a zero coefficient. 
Table 4: Sensitivity of Emerging Market (EM) Stocks to Non-EM World Stock Index

(January 1992 to December 2009)

$$
\Delta p_{t}^{E M \cdot S t o c k}=\alpha+\beta_{0} \cdot \Delta p_{t}^{\text {non-EM-Stock }}+\varepsilon_{t}
$$

$\begin{array}{lcc}\underline{\text { EM Stock Price Index }} & \underline{\beta_{0}} & \underline{\mathrm{R}^{2}} \\ \text { All Emerging Markets } & 1.280 & 0.608 \\ & (0.000) & \\ \text { Latin America } & 1.424 & 0.502 \\ & (0.000) & \\ \text { Asia } & 1.201 & 0.466 \\ & (0.000) & \\ \text { Europe, Mid-East, and Africa } & 1.303 & 0.476 \\ & (0.000) & \end{array}$

Notes: Data are log changes in month-end stock price indexes from MSCI, measured in dollars. The figure in parentheses below each coefficient estimate is a P-value for a two-tailed test for a null hypothesis of a zero coefficient. 


\section{Table 5: Sensitivity of EM Bond Prices to U.S. Corporate Bond Prices over Time}

\section{(January 1992 to December 2009)}

$$
\left(\Delta p_{t}^{\text {EM.Sovereign }}-\Delta p_{t}^{\text {Treasury }}\right)=\alpha+\left(\beta_{0}+\beta_{t} \cdot t\right) \cdot\left(\Delta p_{t}^{\text {U.S.Corporate }}-\Delta p_{t}^{\text {Treasury }}\right)+\varepsilon_{t}
$$

and

$$
E\left(\varepsilon_{t}^{2}\right)=V_{0}+V_{t} \cdot t
$$

$\begin{array}{lccccc}\underline{\text { EM Sovereign Bond Index }} & \underline{\beta_{0}} & \underline{\beta_{t}} & \underline{\mathrm{V}_{0}} & \underline{\mathrm{V}_{\underline{t}}} & \underline{\mathrm{R}^{2}} \\ \text { All Emerging Markets } & 1.090 & -0.062 & 13.929 & -1.421 & 0.326 \\ & (0.000) & (0.002) & (0.000) & (0.059) & \\ \text { Latin America } & 1.097 & -0.061 & 15.247 & -1.298 & 0.309 \\ & (0.000) & (0.003) & (0.000) & (0.020) & \\ \text { Asia } & & & & & \\ & 0.621 & 0.001 & 7.420 & -0.689 & 0.347 \\ & (0.000) & (0.971) & (0.000) & (0.014) & \\ \text { Europe, Mid-East, and Africa } & 1.364 & -0.102 & 22.797 & -2.431 & 0.283 \\ & (0.000) & (0.000) & (0.015) & (0.175) & \end{array}$

Notes: These regression estimates are based on month-end data on log changes in bond price indexes, less the log change in a price index for the 6-year U.S. Treasury bond. Bond indexes are from Merrill Lynch and measured in dollars. The figure in parentheses below each coefficient estimate is a P-value for a two-tailed test for a null hypothesis of a zero coefficient. The time trend $(\mathrm{t})$ is at an annual frequency and crosses zero in the middle of the sample. 


\section{Table 6: Sensitivity of EM Stock Indexes to U.S. Corporate Bond Prices over Time}

\section{(January 1992 to December 2009)}

$$
\Delta p_{t}^{E M \cdot \text { Stock }}=\alpha+\left(\beta_{0}+\beta_{t} \cdot t\right) \cdot\left(\Delta p_{t}^{\text {U.S.Corporate }}-\Delta p_{t}^{\text {Treasury }}\right)+\varepsilon_{t}
$$

and

$$
E\left(\varepsilon_{t}^{2}\right)=V_{0}+V_{t} \cdot t
$$

$\begin{array}{lccccc}\underline{\text { EM Stock Price Index }} & \underline{\beta}_{0} & \underline{\beta_{t}} & \underline{\mathrm{V}_{0}} & \underline{\mathrm{V}_{\underline{t}}} & \underline{\underline{\mathrm{R}}^{2}} \\ \text { All Emerging Markets } & 1.661 & -0.051 & 31.971 & 0.029 & 0.376 \\ & (0.000) & (0.097) & (0.000) & (0.969) & \\ \text { Latin America } & 1.984 & -0.072 & 51.787 & -1.605 & 0.337 \\ & (0.000) & (0.062) & (0.000) & (0.158) & \\ \text { Asia } & 1.398 & -0.023 & 43.482 & -0.978 & 0.270 \\ & (0.000) & (0.525) & (0.000) & (0.318) & \\ \text { Europe, Mid-East, and Africa } & 1.655 & -0.034 & 46.883 & -0.590 & 0.314 \\ & (0.000) & (0.358) & (0.000) & (0.574) & \end{array}$

Notes: These regression estimates are based on month-end data on log changes in price indexes. The U.S. Treasury bond price index is for a 6-year maturity. Bond indexes are from Merrill Lynch and stock indexes are from MSCI, with both measured in dollars. The figure in parentheses below each coefficient estimate is a P-value for a twotailed test for a null hypothesis of a zero coefficient. The time trend $(t)$ is at an annual frequency and crosses zero in the middle of the sample. 
Table 7: Sensitivity of EM Stock Indexes to Non-EM World Stock Index over Time

\section{(January 1992 to December 2009)}

$$
\Delta p_{t}^{E M \cdot \text { Stock }}=\alpha+\left(\beta_{0}+\beta_{t} \cdot t\right) \cdot \Delta p_{t}^{\text {non-EM.Stock }}+\varepsilon_{t}
$$

and

$$
E\left(\varepsilon_{t}^{2}\right)=V_{0}+V_{t} \cdot t
$$

$\begin{array}{lccccc}\underline{\text { EM Stock Price Index }} & \underline{\beta}_{0} & \underline{\beta_{\mathrm{t}}} & \underline{\mathrm{V}_{0}} & \underline{\mathrm{V}_{\underline{t}}} & \underline{\mathrm{R}^{2}} \\ \text { All Emerging Markets } & 1.203 & 0.030 & 20.745 & -1.150 & 0.617 \\ & (0.000) & (0.027) & (0.000) & (0.017) & \\ \text { Latin America } & 1.356 & 0.027 & 39.284 & -2.643 & 0.507 \\ & (0.000) & (0.159) & (0.000) & (0.004) & \\ \text { Asia } & 1.116 & 0.033 & 31.946 & -1.952 & 0.475 \\ & (0.000) & (0.054) & (0.000) & (0.005) & \\ \text { Europe, Mid-East, and Africa } & 1.173 & 0.051 & 35.363 & -2.068 & 0.495 \\ & (0.000) & (0.005) & (0.000) & (0.006) & \end{array}$

Notes: Data are log changes in month-end stock price indexes from MSCI, measured in dollars. The figure in parentheses below each coefficient estimate is a P-value for a two-tailed test for a null hypothesis of a zero coefficient. The time trend $(\mathrm{t})$ is at an annual frequency and crosses zero in the middle of the sample. 
Table 8: EM Sovereign Bond Prices during Large Declines in U.S. Corporate Bond Prices

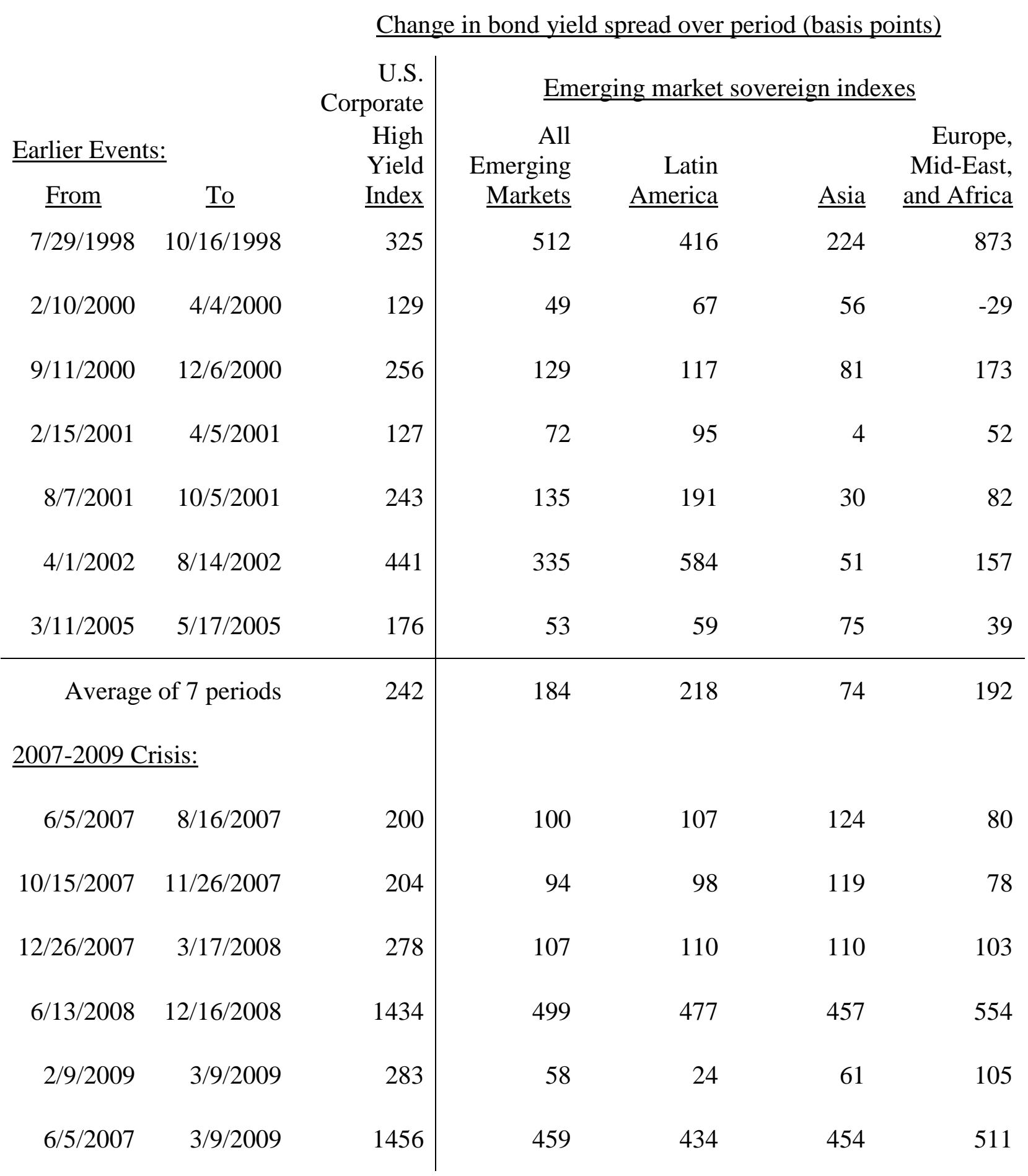

Notes: Changes in spreads are adjusted to remove the effect of month-end compositional changes in the Merrill Lynch bond indexes, and thus do not correspond precisely to the figures plotted in Exhibit 7 (which include these structural breaks). The periods chosen are peak-to-trough declines since January 1992 of at least 5 percent in the Merrill Lynch High-Yield Bond price index, net of the 6-year Treasury price index, roughly corresponding to a widening in the yield spread of 100 basis points or more (see Appendix for details). 
Table 9: Stock Prices during Periods of Large Declines in U.S. Corporate Bond Prices

\section{Change in stock market index over period (percent)}

\begin{tabular}{|c|c|c|c|c|c|c|}
\hline & \multirow[b]{2}{*}{$\begin{array}{r}\text { Non-EM } \\
\text { World }\end{array}$} & \multicolumn{4}{|c|}{ Emerging markets } \\
\hline $\begin{array}{c}\text { Earlier Even } \\
\text { From }\end{array}$ & $\underline{\text { To }}$ & & All EM & $\begin{array}{r}\text { Latin } \\
\text { America } \\
\end{array}$ & $\underline{\text { Asia }}$ & $\begin{array}{r}\text { Mideast } \\
\text { and Africa } \\
\end{array}$ \\
\hline 7/29/1998 & 10/16/1998 & -7.2 & -20.5 & -27.2 & -6.1 & -35.3 \\
\hline $2 / 10 / 2000$ & $4 / 4 / 2000$ & 3.0 & -8.2 & -8.8 & -8.5 & -4.6 \\
\hline $9 / 11 / 2000$ & $12 / 6 / 2000$ & -8.1 & -17.1 & -16.0 & -20.3 & -12.8 \\
\hline $2 / 15 / 2001$ & 4/5/2001 & -11.2 & -19.0 & -12.5 & -21.8 & -22.4 \\
\hline 8/7/2001 & $10 / 5 / 2001$ & -11.0 & -16.5 & -21.4 & -15.1 & -17.6 \\
\hline 4/1/2002 & $8 / 14 / 2002$ & -17.5 & -15.8 & -32.6 & -10.7 & -11.5 \\
\hline 3/11/2005 & $5 / 17 / 2005$ & -4.8 & -8.5 & -7.1 & -6.0 & -11.5 \\
\hline Averag & of 7 periods & -8.1 & -15.1 & -18.0 & -12.6 & -16.5 \\
\hline $2007-2009$ & isis: & & & & & \\
\hline 6/5/2007 & $8 / 16 / 2007$ & -9.3 & -3.9 & -16.0 & 5.1 & 3.1 \\
\hline $10 / 15 / 2007$ & $11 / 26 / 2007$ & -6.7 & -6.5 & -9.3 & -11.6 & -2.0 \\
\hline $12 / 26 / 2007$ & $3 / 17 / 2008$ & -13.7 & -8.0 & -1.5 & -12.9 & -9.1 \\
\hline $6 / 13 / 2008$ & $12 / 16 / 2008$ & -37.2 & -51.8 & -54.8 & -44.5 & -60.2 \\
\hline 2/9/2009 & 3/9/2009 & -21.5 & -9.4 & -8.4 & -8.7 & -2.5 \\
\hline 6/5/2007 & 3/9/2009 & -57.6 & -53.1 & -46.5 & -51.2 & -61.5 \\
\hline
\end{tabular}

Notes: The periods chosen are peak-to-trough declines since January 1992 of at least 5 percent in the Merrill Lynch High-Yield Bond price index, net of the 6-year Treasury price index, roughly corresponding to a widening in the yield spread of 100 basis points or more. Stock market indexes are from MSCI, including the "World Index" of non-EM countries. 